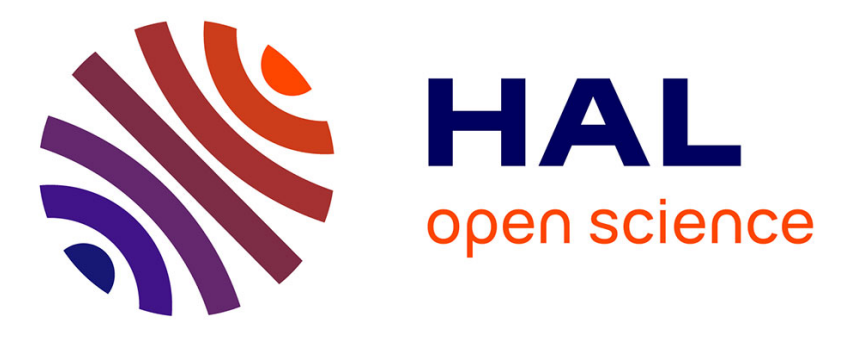

\title{
No alteration of leukocyte telomere length in first episode psychosis
}

\author{
Franck Schürhoff, Cécile Corfdir, Baptiste Pignon, Mohamed Lajnef, \\ Jean-Romain Richard, Elisabeth Marcos, Antoine Pelissolo, Marion Leboyer, \\ Serge Adnot, Stephane Jamain, et al.
}

\section{To cite this version:}

Franck Schürhoff, Cécile Corfdir, Baptiste Pignon, Mohamed Lajnef, Jean-Romain Richard, et al.. No alteration of leukocyte telomere length in first episode psychosis. Psychiatry Research, 2021, 301, pp.113941. 10.1016/j.psychres.2021.113941 . hal-03337995

\section{HAL Id: hal-03337995 https://hal.science/hal-03337995}

Submitted on 8 Sep 2021

HAL is a multi-disciplinary open access archive for the deposit and dissemination of scientific research documents, whether they are published or not. The documents may come from teaching and research institutions in France or abroad, or from public or private research centers.
L'archive ouverte pluridisciplinaire HAL, est destinée au dépôt et à la diffusion de documents scientifiques de niveau recherche, publiés ou non, émanant des établissements d'enseignement et de recherche français ou étrangers, des laboratoires publics ou privés. 


\section{NO ALTERATION OF LEUKOCYTE TELOMERE LENGTH IN FIRST EPISODE PSYCHOSIS}

Franck Schürhoff 1,2,3,4, Cécile Corfdir 1,2,3,4, Baptiste Pignon $2,3,4$, Mohamed Lajnef ${ }^{2,4}$, Jean-Romain Richard 2,4, Elisabeth Marcos 1,5, Antoine Pelissolo 1,2,3,4 , Marion Leboyer 1,2,3,4 , Serge Adnot 1,5, Stephane Jamain 2,4 , Andrei Szöke 2,3,4

1 Université Paris- Est Créteil (UPEC), Créteil, 94000, France,

2 INSERM U955, IMRB, Laboratoire Neuro-psychiatrie translationnelle, F-94010 Creteil, France

${ }^{3}$ AP-HP, Hôpital Henri Mondor, Département Medico-Universitaire de Psychiatrie et d'Addictologie (DMU IMPACT), Federation Hospitalo-Universitaire de Médecine de Precision (FHU ADAPT) F-94010, France

${ }^{4}$ Fondation FondaMental, Créteil, 94000, France

5 INSERM U955, Département de Physiologie - Explorations fonctionnelles, Hôpital Henri Mondor, AP-HP, FHU SENEC, Créteil, 94000, France

+Pr. Franck Schürhoff

Hôpital Albert Chenevier, Groupe hospitalier Henri-Mondor, CHU de Créteil, Assistance Publique-Hôpitaux de Paris (AP-HP), 40 rue de Mesly, 94 000, Créteil, France

franck.schurhoff@inserm.fr

鰋: : $33149813290 ;$ Fax : +33149813059

Abstract : Word count : 142

Body text: Word count: 2821

Key words: First episode psychosis (FEP); schizophrenia; telomere 


\section{Abstract}

Both shorter telomeres and schizophrenia have been associated with a decrease in life expectancy. Furthermore, several studies found a shorter telomere length (TL) in schizophrenia. Understanding whether or not telomere shortening is directly related to pathophysiology of schizophrenia or is a consequence of a cumulative exposure to chronic stress is of major importance. Comparing the TL of subjects at the very beginning of the disease (FEP) and control subjects could help to decide between these two hypotheses. The aim of the present study was to compare TL between FEP subjects $(\mathrm{N}=91)$ and controls $(\mathrm{N}=137)$. After accounting for multiple potential confounders, no significant association was observed between FEP and TL. Our result is consistent with the hypothesis that psycho-social stress / adversities and stressful situations in people with schizophrenia affect TL rather than that telomere erosion contributes to the development of this disorder.

Key words: First episode psychosis (FEP); schizophrenia; telomere 


\section{Introduction}

Schizophrenia is associated with a weighted average of 14.5 years of potential life lost according to a recent meta-analysis (Hjorthøj et al., 2017). This is partly explained by high rates of suicide and an increased risk of cardiovascular diseases. However, all these causes could not fully explain the loss of life expectancy in people suffering from schizophrenia (Galletly, 2017).

On the other hand, life expectancy has been strongly correlated with telomere length (Blackburn, 2010). Telomeres are noncoding structures consisting of DNA TTAGGG tandem repeats and associated proteins located at the end of the chromosomes (de Lange, 2005). Their role is to help preserve genome stability by protecting chromosomal ends from the loss of genetic material (Harari and Kupiec, 2018). The progressive loss of telomeric repeats during cell divisions has led researchers to consider telomeres as molecular clocks that count down to the end of cell growth (Blackburn, 2010).

Age is not the unique factor influencing telomere's length (TL). TL is also influenced by genetic factors (Slagboom et al., 1994) and environmental factors such as smoking (Verde et al., 2015) or psychological stress (Mathur et al., 2016). Telomere shortening has been observed in many diseases such as cardiovascular diseases (D'Mello et al., 2015), type 2 diabetes (Gurung et al., 2018), high blood pressure (Tellechea and Pirola, 2017). Interestingly, these medical conditions that show a high prevalence in subjects with schizophrenia tend to be associated with aging. Schizophrenia itself and its course are associated with physiological changes, which have been associated with normal aging. Such changes include hyperlipidemia, decreased bone density, insulin resistance, cortical atrophy, thinning and wrinkling of the skin, increased blood pressure and decreased muscle mass (Kirkpatrick and Galderisi, 2008). Another potential link between schizophrenia and shortening TL might be through oxidative stress, which is suspected to play a role in the pathophysiology of schizophrenia (Hardingham and Do, 2016; Steullet et al., 2016) and might also accelerate the physiological process of telomere erosion in schizophrenia. 
The fact that both shorter telomeres and schizophrenia have been associated with a decrease in life expectancy has fueled the interest in the study of TL in schizophrenia. Indeed, demonstrating such a relation might improve understanding of the increased mortality and morbidity, improve diagnosis and hopefully suggest means for prevention and/or treatment.

To date, the majority of the studies found a decrease in TL in subjects with schizophrenia compared to control subjects (Czepielewski et al., 2016; Fernandez-Egea et al., 2009; Galletly, 2017; Kao et al., 2008; Kota et al., 2015; Pawelczyk et al., 2015; Rao et al., 2016; Yu et al., 2008) suggesting that telomeres play a role in the pathophysiology of schizophrenia. However, other studies (Li et al., 2015; Malaspina et al., 2014; Mansour et al., 2009; Monroy-Jaramillo et al., 2017; Riley et al., 2018; Wolkowitz et al., 2017) have not been able to demonstrate a significant difference in TL between subjects with schizophrenia and controls. In addition, three studies (Cui et al., 2017; Maurya et al., 2017a; Nieratschker et al., 2013) found an opposite result: increased TL in subjects with schizophrenia. Several meta-analyses have been published on TL in schizophrenia leading to different conclusions (Lin, 2015; Omidpanah et al., 2019; Polho et al., 2015; Rao et al., 2016; Russo et al., 2018). Three of them conclude that TL is decreased in schizophrenia while, two others (Li et al., 2015; Omidpanah et al., 2019) do not. To explain, these discrepant results, the most recent meta-analysis (Omidpanah et al., 2019) suggests that different subtypes of schizophrenia could have specific relationship with TL, while in the studies used for meta-analyses, patients were not categorized according to disease sub-types.

Furthermore, the classic case-control studies that include subjects in different stages of the disorder might add to the confusion because of the presence in variable proportion or for variable durations of potential confounding factors like medications (Porton et al., 2008; Rao et al., 2016), duration of illness and unhealthy lifestyles (e.g., poor diet, smoking). All these factors may impact upon rates of telomere shortening (Maurya et al., 2017a; Yu et al., 2008) and confound the association between schizophrenia and TL. 
In order to overcome these difficulties, some authors (Çevik et al., 2019; Czepielewski et al., 2016) have studied TL, considered as an intermediate phenotype, in non-affected first-degree relatives of schizophrenia subjects. This strategy offers several advantages, since subjects are not impacted by any of the afore-mentioned confounding factors (Braff et al., 2007; Gottesman and Gould, 2003). Çevik et al. (2019) found that first-degree relatives of schizophrenic subjects had significantly longer TL compared to both subjects with schizophrenia and controls. Conversely, Czepielewsi et al. (2016) found that unaffected relatives did not significantly differ in TL from subjects with schizophrenia, whereas individuals with schizophrenia had shorter TL compared to controls. Only one study has been conducted in ultra-high risk (UHR) subjects for psychosis and found that they had shorter TL compared to control subjects (Maurya et al., 2017b). Although this study avoids confounding from medication, it's relevance to schizophrenia is diminished by the fact that most of UHR subjects do not develop schizophrenia (Addington et al., 2015). Thus, the interpretation of this finding is not clear and needs to be further explored.

Comparing the TL of subjects at the very beginning of the disease (FEP) to the general population could help to minimize potential biases (medication, hospitalizations, etc.) and may be more informative about a causative risk mechanism for schizophrenia. To our knowledge, only two studies have investigated the TL in FEP subjects (Li et al., 2015; Maurya et al., 2017a). In both studies, the TL of FEP subjects was not significantly different from TL in control subjects. However, these two studies had also limitations that might explain the negative results. For example, one of the studies excluded subjects with comorbid addiction, which given the high frequency of substance use disorders in schizophrenia, might have rendered the sample nonrepresentative of the disorder ( $\mathrm{Li}$ et al., 2015). In the other sample, the authors did not account for potential differences in ethnicity, which might have influenced the result (Maurya et al., 2017a). The aim of the present study was to further explore the relationship between TL and psychotic disorders by comparing TL between FEP subjects and controls after adjusting for several potential confounding factors. 


\section{Material and methods}

\subsection{Subjects}

The present study is part of a large effort designed to explore gene-environment interactions in the aetiology of psychosis (European network of national schizophrenia networks studying Gene-Environment interaction: http://www.eu-gei.eu). Our study is based on the data collected in the French centers. Data were collected between June $1^{\text {st }} 2010$ and May $31^{\text {st }} 2014$ in three French catchment areas: Clermont-Ferrand surroundings, Créteil (in the suburb of Paris) and Paris.

Patients presenting with their first episode of psychosis were identified by trained researchers who carried out regular checks across the mental health services within the 3 catchment areas. Patients were eligible if they were aged 18-65 years and resident within the study areas at the time of their first presentation with a diagnosis of psychosis by ICD-10 criteria (F20-F33); details are provided in previous publications (Di Forti et al., 2019; Jongsma et al., 2018; Szöke et al., 2014). Cases that accepted to participate were interviewed using the Diagnostic Interview for Genetic Studies (DIGS) (Nurnberger et al., 1994; Preisig et al., 1999) and received a researchbased diagnosis. Patients were excluded if they had been previously treated for psychosis or if they met criteria for organic psychosis (F09) or for psychotic symptoms resulting from acute intoxication (F1X.5).

Controls were recruited using quota sampling strategies. Accurate local demographic data were used to ensure the sample's representativeness of the three catchment areas in terms of age, gender and ethnicity. Control subjects were also between 18 and 65 years old and were excluded if they had previously received a diagnosis of a psychotic disorder. Given the general 
aims of the global European study, subjects born outside mainland France were oversampled (twofold).

All participants provided informed written consent. Ethical approval was provided by the Comité de Protection des Personnes (CPP Ile de France IX) under the project number: 2010A00161-38. The EU-GEI project is funded by the European Community's Seventh Framework Program under grant agreement $\mathrm{n}^{\circ}$ HEALTH-F2-2010-241909. The funder had no involvement in the study design, data collection, analysis, interpretation of findings, manuscript preparation or the decision to submit the paper for publication.

\subsection{Assessments}

Data collected from FEP and control subjects which included variables of interest for the present study were: age, gender, weight, smoking status, ethnicity, paternal and maternal ages at birth of the subject. All participants provided a blood sample for measurement of leukocyte telomere length.

\subsection{Measurement of leukocyte telomere length}

Leukocyte DNA was extracted from peripheral blood samples and kept at $-80^{\circ} \mathrm{C}$ before use. The genomic DNA was isolated from whole blood using Maxwell 16 semi-automated system (Promega) following the manufacturer's instructions.

The telomere length was measured by realtime PCR (qPCR) according to the original method by Cawthon (Cawthon, 2002). The samples were all run in triplicates in a real time PCR system with QuantStudio $^{\mathrm{TM}} 6$ Flex Real-time PCR System. The sequences for the primers for telomeres et 36B4 were: Tel F, 5' CGGTTTGTTTGGGTTTGGGTTTGGGTTTGGGTTTGGGTT-3', 300 nM ; Tel R, 5'GGCT TGCCTTACCCTTACCCTTACCCTTACCCT-3', $300 \quad \mathrm{nM} \quad ; \quad 36 \mathrm{~B} 4 \mathrm{~F}, \quad$ 5'CAGCA AGTGGGAAGGTGTAATCC-3', 300 nM ; and 36B4R, 5'-CCATTCTATCAACGGGTACAA-3', 300 nM. 
The measurement consists of determining the relative ratio ( $\mathrm{T} / \mathrm{S}$ ratio) of number of telomeric copies to a single copy gene, using the comparative $\mathrm{Ct}$ method $\left(\mathrm{T} / \mathrm{S}=2^{-\Delta \Delta \mathrm{Ct}}\right)$, which reflects the number of copies of telomere in each cell in a assay. This method amplifies the telomeric (T) DNA and a single-copy (S) control gene (36B4) was used to normalize values.

\subsection{Statistical analyses}

Demographic and clinical characteristics were compared between FEP and controls using the chi-square, Mann-Whitney's or Student's t test, as appropriate. Due to a skewed distribution of TL (assessed by The Shapiro-Wilk test), non-parametric tests were used to study the relationships between TL and other variables. Spearman correlation analyses were used to study the relationship between TL and continuous variables. A logarithmic transformation of TL was performed to achieve the normality assumed for parametric procedures. Linear regression model was used to examine the relationship between TL and the group as the predictive variable. Age, gender, ethnicity, smoking status, paternal and maternal ages were included as the confounding factors. A p-value of $\leq 0.05$ was considered statistically significant. Analyses were performed using R software (version 3.6) (R Core Team, 2013).

\section{Results}

The sample was composed of 91 FEP subjects and 137 control subjects. Demographic and clinical characteristics of the two samples are summarized in Table 1. The control group were significantly older than the FEP group $(38.7+/-14$ and $31.5+/-10.7$, respectively, $\mathrm{p}<0.001)$. The groups also differed significantly according to gender $(p=0.01)$, smoking status $(p<0.01)$ and ethnicity ( $\mathrm{p}<0.001$ ). Cigarette smoking status were defined as either "never" or "current/past" as in Malaspina et al. (2014). Leukocyte TL was negatively correlated with age $($ Spearman rho $=-0.19, \mathrm{p}=0.03)$ and positively correlated with paternal age $($ Spearman rho $=$ $0.16 ; \mathrm{p}=0.01)$. There was no significant correlation between $\mathrm{TL}$ and the other potential confounding variables (maternal age, weight, smoking status, gender and ethnicity). 
In an unadjusted model, the groups did not differ significantly according to T/S ratio $(0.76+/-$ 0.26 vs. $0.71+/-0.25$ for FEP cases and controls respectively; $p=0.23$ ) (Figure 1). After adjustment for age, paternal age, gender, smoking status and ethnicity, the results were the same, i.e. TL did not show a significant difference between groups (beta coefficient $=0.26, p=$ 0.63). Subgroup analyses (affective FEP ( $n=22)$ vs. controls and non-affective FEP ( $n=69)$ vs. controls) did not show any significant differences of TL between subgroups and controls $(\mathrm{p}=$ 0.19 and $\mathrm{p}=0.73$ respectively).

INSERT TABLE 1 HERE

INSERT FIGURE 1 HERE

\section{Discussion}

We did not find any significant differences of TL in FEP compared to healthy controls. This finding is consistent with the two previous studies investigating TL in FEP subjects and raises several questions regarding the relationship between telomere erosion and schizophrenia. Indeed, the fact that the majority of studies report shortened TL in schizophrenia (FernandezEgea et al., 2009; Kao et al., 2008; Kota et al., 2015; Yu et al., 2008) but not in FEP subjects could lead to several explanations. It is possible that some confounders that occur or increase after the first episode, including age of subjects, lifestyles, medical comorbidities and antipsychotics use might partly explain a shortened TL in schizophrenia. The inconsistent results in the literature might also suggest that shortened TL is associated only with a specific subtype of schizophrenia (Vaez-Azizi et al., 2015) or depend on the exposure to specific risk factors such as a history of childhood trauma (Aas et al., 2019). Thus, the association between TL and schizophrenia would depend on the proportion of this subtype and/or of the frequency of exposure to specific risk 
factors in the different samples. It is therefore possible that the absence of shortened TL in our study is due to the clinical and/or etiological heterogeneity of this population.

However and more convincingly, two pathophysiological, non-mutually exclusive mechanisms can be proposed to explain the observed data. A first hypothesis is that the acceleration of the physiological process of telomere erosion in schizophrenia is due to the activation of inflammatory processes and oxidative stress as a consequence of schizophrenia per se. The second hypothesis is that reduced TL may be a result of cumulative exposure to chronic stress related to schizophrenia. According to these two hypotheses, telomere erosion may be mild in the early-phase of schizophrenia, since these individuals have short-term exposure to stress and a shorter duration of the illness. Indeed, in healthy individuals, a growing body of evidence has linked chronic stress, inflammatory process, oxidative stress to accelerated shortening of TL (Epel et al., 2004; Price et al., 2013; Tyrka et al., 2015) and it is possible that the stress-mediated telomere erosion might be too small to be detected in FEP patients because they had younger age and shorter duration of illness than subjects with schizophrenia. Based on these both explanations, telomere alterations may be considered as a biomarker of illness progression and might be useful for illness staging.

It is unlikely that our results and those previously reported in FEP could be explained by a lack of statistical power or by the presence of psychotic affective disorders. Indeed, several studies reporting significant reduced TL in non FEP schizophrenia samples have similar or smaller sample sizes than the FEP studies and shorter telomeres have also been described in subjects with affective disorders (Barbé-Tuana et al., 2016; Lima et al., 2015; Simon et al., 2006). However, several limitations should be considered in the interpretation of our results. Leukocyte TL is highly correlated with TL of other tissues, however, we still cannot exclude significantly shorter TL in neural cells. The cross-sectional design of the study makes assessments of telomere trajectory or rate of telomere shortening in individual subjects impossible. The percentage of women is high in the FEP group, and thus, our sample is probably not representative of FEP population. Lastly, although adjustments were made for potential 
confounding variables, the possibility of the influence of unmeasured covariates cannot be excluded.

Overall, our result suggests that reduced TL may not be an intrinsic feature of schizophrenia or associated with risk factors for schizophrenia but rather the result of cumulative exposure to chronic stress (Epel et al., 2004; Savolainen et al., 2012) after the onset of the disorder. In other words, our result is consistent with the hypothesis that psycho-social stress / adversities and stressful situations in people with schizophrenia affect TL rather than that telomere erosion contributes to the development of this disorder. In this case, treatments that prevent exposure and/or vulnerability to stressful life events that ameliorate schizophrenia may also prevent or decelerate telomere erosion. In this perspective, by engaging in a healthy diet and regular activity subjects suffering from schizophrenia could be both promising strategies to protect telomere maintenance and improve health span at old age. It is clear that schizophrenia is associated with a greater exposure to stress factors, altering hypothalamic-pituitary-adrenal axis function, which may produce altered cognition and behaviors (Cherian et al., 2019; Ruby et al., 2017). It remains to be determined how stress and the activity of the hypothalamic-pituitaryadrenal axis influence TL. In addition, the inflammatory process involved in the physiopathology of at least a subgroup of subjects with schizophrenia (for review, see Müller (2018)) could be also responsible of telomere erosion as suggested by previous research (Carrero et al., 2008; Damjanovic et al., 2007; Steullet et al., 2016). Further illuminating the relationship between stress, inflammation and TL is of great interest for psychiatric research and for understanding stress effects in this population. 


\section{Acknowledgements}

The authors have declared that there are no conflicts of interest in relation to the subject of this study.

\section{Funding}

This work was supported by a grant (agreement HEALTH-F2-2010- 241909 (Project EU-GEI)) from the European Community's Seventh Framework Programme. 


\section{References}

Aas, M., Pizzagalli, D.A., Laskemoen, J.F., Reponen, E.J., Ueland, T., Melle, I., Agartz, I., Steen, N.E., Andreassen, O.A., 2019. Elevated hair cortisol is associated with childhood maltreatment and cognitive impairment in schizophrenia and in bipolar disorders. Schizophr. Res. 213, $65-71$.

Addington, J., Liu, L., Buchy, L., Cadenhead, K.S., Cannon, T.D., Cornblatt, B.A., Perkins, D.O., Seidman, L.J., Tsuang, M.T., Walker, E.F., Woods, S.W., Bearden, C.E., Mathalon, D.H., McGlashan, T.H., 2015. North American Prodrome Longitudinal Study (NAPLS 2): The Prodromal Symptoms. J. Nerv. Ment. Dis. 203, 328-335.

Barbé-Tuana, F.M., Parisi, M.M., Panizzutti, B.S., Fries, G.R., Grun, L.K., Guma, F.T., Kapczinski, F., Berk, M., Gama, C.S., Rosa, A.R., 2016. Shortened telomere length in bipolar disorder: a comparison of the early and late stages of disease. Rev. Bras. Psiquiatr. Sao Paulo Braz. 1999 38, 281-286.

Blackburn, E.H., 2010. Telomeres and telomerase: the means to the end (Nobel lecture). Angew. Chem. Int. Ed Engl. 49, 7405-7421.

Braff, D.L., Freedman, R., Schork, N.J., Gottesman, I.I., 2007. Deconstructing Schizophrenia: An Overview of the Use of Endophenotypes in Order to Understand a Complex Disorder. Schizophr. Bull. 33, 21-32.

Carrero, J.J., Stenvinkel, P., Fellström, B., Qureshi, A.R., Lamb, K., Heimbürger, O., Bárány, P., Radhakrishnan, K., Lindholm, B., Soveri, I., Nordfors, L., Shiels, P.G., 2008. Telomere attrition is associated with inflammation, low fetuin-A levels and high mortality in prevalent haemodialysis patients. J. Intern. Med. 263, 302-312.

Cawthon, R.M., 2002. Telomere measurement by quantitative PCR. Nucleic Acids Res. 30, e47.

Çevik, B., Mançe-Çalışır, Ö., Atbaşoğlu, E.C., Saka, M.C., Alptekin, K., Üçok, A., Sırmatel, B., Gülöksüz, S., Tükün, A., van Os, J., Gümüş-Akay, G., 2019. Psychometric liability to psychosis and childhood adversities are associated with shorter telomere length: A study on schizophrenia patients, unaffected siblings, and non-clinical controls. J. Psychiatr. Res. $111,169-185$.

Cherian, K., Schatzberg, A.F., Keller, J., 2019. HPA axis in psychotic major depression and schizophrenia spectrum disorders: Cortisol, clinical symptomatology, and cognition. Schizophr. Res., Stress and Schizophrenia 213, 72-79.

Cui, Y., Prabhu, V.V., Nguyen, T.B., Devi, S.M., Chung, Y.-C., 2017. Longer Telomere Length of T lymphocytes in Patients with Early and Chronic Psychosis. Clin. Psychopharmacol. Neurosci. Off. Sci. J. Korean Coll. Neuropsychopharmacol. 15, 146-152.

Czepielewski, L.S., Massuda, R., Panizzutti, B., da Rosa, E.D., de Lucena, D., Macêdo, D., Grun, L.K., Barbé-Tuana, F.M., Gama, C.S., 2016. Telomere length in subjects with schizophrenia, their unaffected siblings and healthy controls: Evidence of accelerated aging. Schizophr. Res. 174, 39-42.

Damjanovic, A.K., Yang, Y., Glaser, R., Kiecolt-Glaser, J.K., Nguyen, H., Laskowski, B., Zou, Y., Beversdorf, D.Q., Weng, N., 2007. Accelerated Telomere Erosion Is Associated with a Declining Immune Function of Caregivers of Alzheimer's Disease Patients. J. Immunol. Baltim. Md 1950 179, 4249-4254.

de Lange, T., 2005. Shelterin: the protein complex that shapes and safeguards human telomeres. Genes Dev. 19, 2100-2110.

Di Forti, M., Quattrone, D., Freeman, T.P., Tripoli, G., Gayer-Anderson, C., Quigley, H., Rodriguez, V., Jongsma, H.E., Ferraro, L., La Cascia, C., La Barbera, D., Tarricone, I., Berardi, D., Szöke, A., Arango, C., Tortelli, A., Velthorst, E., Bernardo, Miguel, Del-Ben, C.M., Menezes, P.R., Selten, J.-P., Jones, P.B., Kirkbride, J.B., Rutten, B.P., de Haan, L., Sham, P.C., van Os, J., Lewis, C.M., Lynskey, M., Morgan, C., Murray, R.M., Amoretti, S., Arrojo, M., Baudin, G., Beards, S., Bernardo, Miquel, Bobes, J., Bonetto, C., Cabrera, B., Carracedo, A., Charpeaud, 
T., Costas, J., Cristofalo, D., Cuadrado, P., Díaz-Caneja, C.M., Ferchiou, A., Franke, N., Frijda, F., García Bernardo, E., Garcia-Portilla, P., González, E., Hubbard, K., Jamain, S., JiménezLópez, E., Leboyer, M., López Montoya, G., Lorente-Rovira, E., Marcelino Loureiro, C., Marrazzo, G., Martínez, C., Matteis, M., Messchaart, E., Moltó, M.D., Nacher, J., Olmeda, M.S., Parellada, M., González Peñas, J., Pignon, B., Rapado, M., Richard, J.-R., Rodríguez Solano, J.J., Roldán Díaz, L., Ruggeri, M., Sáiz, P.A., Sánchez, E., Sanjuán, J., Sartorio, C., Schürhoff, F., Seminerio, F., Shuhama, R., Sideli, L., Stilo, S.A., Termorshuizen, F., Tosato, S., Tronche, A.M., van Dam, D., van der Ven, E., 2019. The contribution of cannabis use to variation in the incidence of psychotic disorder across Europe (EU-GEI): a multicentre case-control study. Lancet Psychiatry 6, 427-436.

D’Mello, M.J.J., Ross, S.A., Briel, M., Anand, S.S., Gerstein, H., Paré, G., 2015. Association between shortened leukocyte telomere length and cardiometabolic outcomes: systematic review and meta-analysis. Circ. Cardiovasc. Genet. 8, 82-90.

Epel, E.S., Blackburn, E.H., Lin, J., Dhabhar, F.S., Adler, N.E., Morrow, J.D., Cawthon, R.M., 2004. Accelerated telomere shortening in response to life stress. Proc. Natl. Acad. Sci. 101, 17312-17315.

Fernandez-Egea, E., Bernardo, M., Heaphy, C.M., Griffith, J.K., Parellada, E., Esmatjes, E., Conget, I., Nguyen, L., George, V., Stöppler, H., Kirkpatrick, B., 2009. Telomere length and pulse pressure in newly diagnosed, antipsychotic-naive patients with nonaffective psychosis. Schizophr. Bull. 35, 437-442.

Galletly, C.A., 2017. Premature death in schizophrenia: bridging the gap. Lancet Psychiatry 4, 263-265.

Gottesman, I.I., Gould, T.D., 2003. The endophenotype concept in psychiatry: etymology and strategic intentions. Am. J. Psychiatry 160, 636-645.

Gurung, R., Liu, J., Chan, S., Moh, M., Ang, K., Tang, W., Sum, C., Tavintharan, S., Lim, S., SMART2D Study, 2018. Ethnic disparities in relationships of obesity indices with telomere length in Asians with type 2 diabetes. J. Diabetes 11, 386-393.

Harari, Y., Kupiec, M., 2018. Do long telomeres affect cellular fitness? Curr. Genet. 64, 173-176.

Hardingham, G.E., Do, K.Q., 2016. Linking early-life NMDAR hypofunction and oxidative stress in schizophrenia pathogenesis. Nat. Rev. Neurosci. 17, 125-134.

Hjorthøj, C., Stürup, A.E., McGrath, J.J., Nordentoft, M., 2017. Years of potential life lost and life expectancy in schizophrenia: a systematic review and meta-analysis. Lancet Psychiatry 4, 295-301.

Jongsma, H.E., Gayer-Anderson, C., Lasalvia, A., Quattrone, D., Mulè, A., Szöke, A., Selten, J.-P., Turner, C., Arango, C., Tarricone, I., Berardi, D., Tortelli, A., Llorca, P.-M., Haan, L. de, Bobes, J., Bernardo, M., Sanjuán, J., Santos, J.L., Arrojo, M., Del-Ben, C.M., Menezes, P.R., Murray, R.M., Rutten, B.P., Jones, P.B., van Os, J., Morgan, C., Kirkbride, J.B., 2018. Treated incidence of psychotic disorders in the multinational EU-GEI study. JAMA Psychiatry 75, 36-46.

Kao, H.-T., Cawthon, R.M., Delisi, L.E., Bertisch, H.C., Ji, F., Gordon, D., Li, P., Benedict, M.M., Greenberg, W.M., Porton, B., 2008. Rapid telomere erosion in schizophrenia. Mol. Psychiatry 13, 118-119.

Kirkpatrick, B., Galderisi, S., 2008. Deficit schizophrenia: an update. World Psychiatry 7, 143-147. Kota, L.N., Bharath, S., Purushottam, M., Moily, N.S., Sivakumar, P.T., Varghese, M., Pal, P.K., Jain, S., 2015. Reduced telomere length in neurodegenerative disorders may suggest shared biology. J. Neuropsychiatry Clin. Neurosci. 27, e92-96.

Li, Z., Hu, M., Zong, X., He, Y., Wang, D., Dai, L., Dong, M., Zhou, J., Cao, H., Lv, L., Chen, X., Tang, J., 2015. Association of telomere length and mitochondrial DNA copy number with risperidone treatment response in first-episode antipsychotic-naïve schizophrenia. Sci. Rep. 5, 18553.

Lima, I.M.M., Barros, A., Rosa, D.V., Albuquerque, M., Malloy-Diniz, L., Neves, F.S., Romano-Silva, M.A., de Miranda, D.M., 2015. Analysis of telomere attrition in bipolar disorder. J. Affect. Disord. 172, 43-47. 
Lin, P.-Y., 2015. Shortened leukocyte telomere length in patients with schizophrenia is related to disease status. Schizophr. Res. 168, 597-598.

Malaspina, D., Dracxler, R., Walsh-Messinger, J., Harlap, S., Goetz, R.R., Keefe, D., Perrin, M.C., 2014. Telomere length, family history, and paternal age in schizophrenia. Mol. Genet. Genomic Med. 2, 326-331.

Mansour, H.A., Talkowski, M.E., Wood, J., Chowdari, K.V., McClain, L., Prasad, K., Montrose, D., Fagiolini, A., Friedman, E.S., Allen, M.H., Bowden, C.L., Calabrese, J., El-Mallakh, R.S., Escamilla, M., Faraone, S.V., Fossey, M.D., Gyulai, L., Loftis, J.M., Hauser, P., Ketter, T.A., Marangell, L.B., Miklowitz, D.J., Nierenberg, A.A., Patel, J., Sachs, G.S., Sklar, P., Smoller, J.W., Laird, N., Keshavan, M., Thase, M.E., Axelson, D., Birmaher, B., Lewis, D., Monk, T., Frank, E., Kupfer, D.J., Devlin, B., Nimgaonkar, V.L., 2009. Association study of 21 circadian genes with bipolar I disorder, schizoaffective disorder, and schizophrenia. Bipolar Disord. 11, 701-710.

Mathur, M.B., Epel, E., Kind, S., Desai, M., Parks, C.G., Sandler, D.P., Khazeni, N., 2016. Perceived stress and telomere length: A systematic review, meta-analysis, and methodologic considerations for advancing the field. Brain. Behav. Immun. 54, 158-169.

Maurya, P., Rizzo, L., Xavier, G., Tempaku, P., Ota, V., Santoro, M., Spíndola, L., Moretti, P., Mazzoti, D., Gadelha, A., Gouvea, E., Noto, C., Maes, M., Cordeiro, Q., Bressan, R., Brietzke, E., Belangero, S., 2017a. Leukocyte telomere length variation in different stages of schizophrenia. J. Psychiatr. Res. 96, 218-223.

Maurya, P., Rizzo, L., Xavier, G., Tempaku, P., Zeni-Graiff, M., Santoro, M., Mazzotti, D., Zugman, A., Pan, P., Noto, C., Maes, M., Asevedo, E., Mansur, R., Cunha, G., Gadelha, A., Bressan, R., Belangero, S., Brietzke, E., 2017b. Shorter leukocyte telomere length in patients at ultra high risk for psychosis. Eur. Neuropsychopharmacol. 27, 538-542.

Monroy-Jaramillo, N., Rodríguez-Agudelo, Y., Aviña-Cervantes, L.C., Roberts, D.L., Velligan, D.I., Walss-Bass, C., 2017. Leukocyte telomere length in Hispanic schizophrenia patients under treatment with olanzapine. J. Psychiatr. Res. 90, 26-30.

Müller, N., 2018. Inflammation in Schizophrenia: Pathogenetic Aspects and Therapeutic Considerations. Schizophr. Bull. 44, 973-982.

Nieratschker, V., Lahtinen, J., Meier, S., Strohmaier, J., Frank, J., Heinrich, A., Breuer, R., Witt, S.H., Nöthen, M.M., Rietschel, M., Hovatta, I., 2013. Longer telomere length in patients with schizophrenia. Schizophr. Res. 149, 116-120.

Nurnberger, J.I., Blehar, M.C., Kaufmann, C.A., York-Cooler, C., Simpson, S.G., Harkavy-Friedman, J., Severe, J.B., Malaspina, D., Reich, T., 1994. Diagnostic interview for genetic studies. Rationale, unique features, and training. NIMH Genetics Initiative. Arch. Gen. Psychiatry 51, 849-859; discussion 863-864.

Omidpanah, N., Darvishi, F.Z., Saadat, M., 2019. No alteration in leukocyte telomere length in schizophrenia; evidence from a meta-analysis. Schizophr. Res. 208, 447-448.

Pawelczyk, T., Szymanska, B., Grancow-Grabka, M., Kotlicka-Antczak, M., Pawelczyk, A., 2015. Telomere length in blood cells is related to the chronicity, severity, and recurrence rate of schizophrenia. Neuropsychiatr. Dis. Treat. 11, 1493-1503.

Polho, G.B., De-Paula, V.J., Cardillo, G., dos Santos, B., Kerr, D.S., 2015. Leukocyte telomere length in patients with schizophrenia: A meta-analysis. Schizophr. Res. 165, 195-200.

Porton, B., DeLisi, L.E., Bertisch, H.C., Ji, F., Gordon, D., Li, P., Benedict, M.M., Greenberg, W.M., Kao, H.-T., 2008. Telomerase Levels in Schizophrenia: A Preliminary Study. Schizophr. Res. $106,242-247$.

Preisig, M., Fenton, B.T., Matthey, M.-L., Berney, A., Ferrero, F., 1999. Diagnostic interview for genetic studies (DIGS): inter-rater and test-retest reliability of the French version. Eur. Arch. Psychiatry Clin. Neurosci. 249, 174-179.

Price, L.H., Kao, H.-T., Burgers, D.E., Carpenter, L.L., Tyrka, A.R., 2013. Telomeres and early-life stress: an overview. Biol. Psychiatry 73, 15-23.

R Core Team, 2013. R: A language and environment for statistical computing. R Foundation for Statistical Computing, version 3.3.0. Vienna, Austria. 
Rao, S., Kota, L.N., Li, Z., Yao, Y., Tang, J., Mao, C., Jain, S., Xu, Y., Xu, Q., 2016. Accelerated leukocyte telomere erosion in schizophrenia: Evidence from the present study and a meta-analysis. J. Psychiatr. Res. 79, 50-56.

Riley, G., Perrin, M., Vaez-Azizi, L.M., Ruby, E., Goetz, R.R., Dracxler, R., Walsh-Messinger, J., Keefe, D.L., Buckley, P.F., Szeszko, P.R., Malaspina, D., 2018. Telomere length and early trauma in schizophrenia. Schizophr. Res. 199, 426-430.

Ruby, E., Rothman, K., Corcoran, C., Goetz, R.R., Malaspina, D., 2017. Influence of early trauma on features of schizophrenia. Early Interv. Psychiatry 11, 322-333.

Russo, P., Prinzi, G., Proietti, S., Lamonaca, P., Frustaci, A., Boccia, S., Amore, R., Lorenzi, M., Onder, G., Marzetti, E., Valdiglesias, V., Guadagni, F., Valente, M.G., Cascio, G.L., Fraietta, S., Ducci, G., Bonassi, S., 2018. Shorter telomere length in schizophrenia: Evidence from a realworld population and meta-analysis of most recent literature. Schizophr. Res. 202, 37-45.

Savolainen, K., Räikkönen, K., Kananen, L., Kajantie, E., Hovatta, I., Lahti, M., Lahti, J., Pesonen, A.K., Heinonen, K., Eriksson, J.G., 2012. History of mental disorders and leukocyte telomere length in late adulthood: the Helsinki Birth Cohort Study (HBCS). J. Psychiatr. Res. 46, 1346-1353.

Simon, N.M., Hoge, E.A., Fischmann, D., Worthington, J.J., Christian, K.M., Kinrys, G., Pollack, M.H., 2006. An open-label trial of risperidone augmentation for refractory anxiety disorders. J. Clin. Psychiatry 67, 381-385.

Slagboom, P.E., Droog, S., Boomsma, D.I., 1994. Genetic determination of telomere size in humans: a twin study of three age groups. Am. J. Hum. Genet. 55, 876-882.

Steullet, P., Cabungcal, J.H., Monin, A., Dwir, D., O’Donnell, P., Cuenod, M., Do, K.Q., 2016. Redox dysregulation, neuroinflammation, and NMDA receptor hypofunction: A "central hub" in schizophrenia pathophysiology? Schizophr. Res. 176, 41-51.

Szöke, A., Charpeaud, T., Galliot, A.-M., Vilain, J., Richard, J.-R., Leboyer, M., Llorca, P.-M., Schürhoff, F., 2014. Rural-urban variation in incidence of psychosis in France: a prospective epidemiologic study in two contrasted catchment areas. BMC Psychiatry 14, 78.

Tellechea, M.L., Pirola, C.J., 2017. The impact of hypertension on leukocyte telomere length: a systematic review and meta-analysis of human studies. J. Hum. Hypertens. 31, 99-105.

Tyrka, A.R., Carpenter, L.L., Kao, H.-T., Porton, B., Philip, N.S., Ridout, S.J., Ridout, K.K., Price, L.H., 2015. Association of Telomere Length and Mitochondrial DNA Copy Number in a Community Sample of Healthy Adults. Exp. Gerontol. 66, 17-20.

Vaez-Azizi, L.M., Ruby, E., Dracxler, R., Rothman, K., Perrin, M., Walsh-Messinger, J., Antonius, D., Goetz, R.R., Goetz, D.M., Keefe, D.L., Malaspina, D., 2015. Telomere length variability is related to symptoms and cognition in schizophrenia. Schizophr. Res. 164, 268-269.

Verde, Z., Reinoso-Barbero, L., Chicharro, L., Garatachea, N., Resano, P., Sánchez-Hernández, I., Rodríguez González-Moro, J.M., Bandrés, F., Santiago, C., Gómez-Gallego, F., 2015. Effects of cigarette smoking and nicotine metabolite ratio on leukocyte telomere length. Environ. Res. 140, 488-494.

Wolkowitz, O.M., Jeste, D.V., Martin, A.S., Lin, J., Daly, R.E., Reuter, C., Kraemer, H., 2017. Leukocyte telomere length: Effects of schizophrenia, age, and gender. J. Psychiatr. Res. 85, 42-48.

Yu, W.-Y., Chang, H.-W., Lin, C.-H., Cho, C.-L., 2008. Short telomeres in patients with chronic schizophrenia who show a poor response to treatment. J. Psychiatry Neurosci. JPN 33, 244-247. 
Table 1: Description and comparison of the FEP subjects vs. control subjects

\begin{tabular}{|c|c|c|c|c|c|}
\hline & $\begin{array}{c}\text { FEP } \\
(n=91)\end{array}$ & $\begin{array}{l}\text { Controls } \\
(n=137)\end{array}$ & IC 95\% & $\begin{array}{c}\text { Chi }^{2} \text { or Mann- } \\
\text { Whitney } \\
\text { statistic test }\end{array}$ & $\mathbf{p}$ \\
\hline Age (years) & $31.5(+/-10.8)$ & $38.7(+/-14.1)$ & $\begin{array}{l}29.3 \\
33.7)^{*} \\
(36.4-41.1)\end{array}$ & 3.80 & $\mathrm{p}<0.001$ \\
\hline Sex (\% of men) & $37.4 \%$ & $54.7 \%$ & $\begin{array}{l}(28-47.8)^{*} \\
(46.3-63)\end{array}$ & 6.6 & $\mathrm{p}=0.01$ \\
\hline Smoking (\% of smokers) & $60.9 \%$ & $34.1 \%$ & $\begin{array}{l}(50.2 \\
70.7)^{*} \\
(26.5-42.5)\end{array}$ & 15.4 & $\mathrm{p}<0.01$ \\
\hline Paternal age (Years) & $33.2(+/-9.2)$ & $31.1(+/-9.2)$ & $\begin{array}{l}(31.1-35.4)^{*} \\
(29.7-32.5)\end{array}$ & 1.50 & $p=0.13$ \\
\hline Maternal age (years) & $27.7(+/-6.6$ & $26.9(+/-5.9)$ & $\begin{array}{l}(26.2 \\
29.2)^{*} \\
(25.9-27.9)\end{array}$ & 0.69 & $p=0.49$ \\
\hline Ethnicity (\% of Caucasians) & $37.1 \%$ & $70.8 \%$ & $\begin{array}{l}(27.6 \\
47.7)^{*} \\
(62.7-77.8)\end{array}$ & 25.11 & $\mathrm{P}<0.001$ \\
\hline Weight (kgs) & $70.4(+/-13.7)$ & $73.1(+/-16)$ & $\begin{array}{l}(67.2 \\
73.5)^{*} \\
(69.9-76.4)\end{array}$ & 1.06 & $\mathrm{p}=0.29$ \\
\hline Telomere length $(\mathrm{T} / \mathrm{S})$ & $0.76(+/-0.26)$ & $0.71(+/-0.25)$ & $\begin{array}{l}(0.71 \\
0.82)^{*} \\
(0.67-0.76)\end{array}$ & 1.20 & $\mathrm{p}=0.23$ \\
\hline
\end{tabular}

* FEP group 


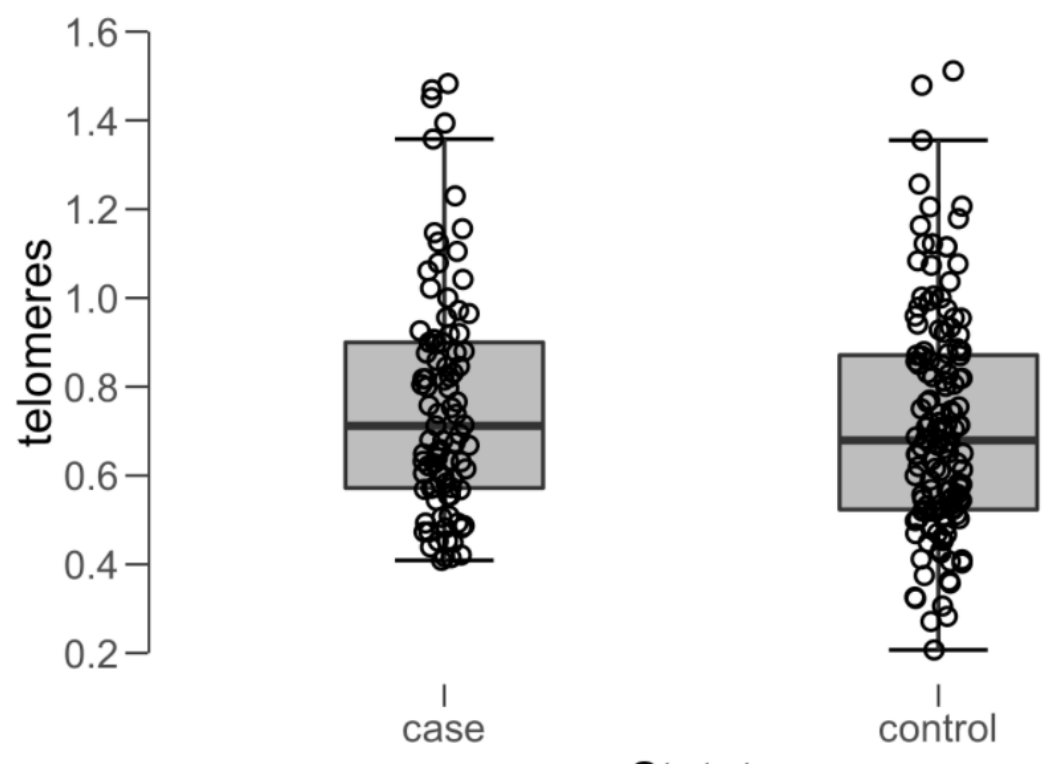

Fig 1: Telomere Length (TL) in FEP (case, $N=91$ ) and healthy controls ( $N=137$ )

Bold line as mean and error bars as standard deviation 